\title{
Views on Water Management from Students of Different Faculties at the University of Calgary: Developing Water Policies Using Focus Groups
}

\author{
Jacqueline Noga $^{1} \&$ Gregor Wolbring ${ }^{1}$ \\ ${ }^{1}$ Faculty of Medicine, University of Calgary, Calgary, Canada \\ Correspondence: Gregor Wolbring, Faculty of Medicine, University of Calgary, Calgary, Alta., T2N 4N1, \\ Canada. Tel: 403-210-7083. E-mail: gwolbrin@ucalgary.ca
}

Received: September 2, 2014

Accepted: September 10, 2014 Online Published: September 24, 2014

doi:10.5539/jsd.v7n5p189

URL: http://dx.doi.org/10.5539/jsd.v7n5p189

\begin{abstract}
Public participation in water management provides greater understanding of the challenges faced by a community and often leads to greater uptake of any new policies. Water management is a critical part of water security, and water management benefits from public participation. The objective of this research is to gain insight into the perceptions of water held by students at University of Calgary, and their beliefs about water management in Calgary. Focus groups were conducted with Engineering, Medical Science, Environmental Science, and Economics students of the University of Calgary. The focus groups were audio-recorded and transcribed verbatim. The majority of the discussion was about decreasing Calgary's current water consumption and ways to go about doing this. This included discussion about the price of water, the use of water-efficient technology, legal regulations, incentives, and increasing awareness about water issues. Each student group had some predominant discussion and ideas unique to their group, and similarities were found amongst the different programs, particularly between the Engineering and Environmental Science groups. The students considered water as primarily a natural resource and a public resource, and some groups also agreed that water is a human right. The ideas about water management indicate that the students wish to see water used more sustainably, however the groups debated different methods for introducing change based on what kind of intervention was thought to be the most effective. The perspectives of the students offered a range of ideas that could provide insight into future management.
\end{abstract}

Keywords: water management, public participation, students

\section{Introduction}

\subsection{Introduction to and Significance of Water Management}

Water is one of the most basic human needs: clean water for drinking and sanitation is critical for health and for life. Yet clean water is not always accessible or readily available. Furthermore, as evidenced by the 2013 floods in Alberta, water can have a detrimental impact if it comes in the form of a natural disaster and the human population is ill-prepared to deal with it ("The 2013 Great Alberta Flood: Progress Report on Actions to Mitigate, Manage and Control Flooding," 2014). Water security means having a secure and stable source of water and is important to consider when addressing water management (Grey \& Sadoff, 2007). Water management is critical in adapting to a changing and fluctuating water cycle (R. B. Jackson et al., 2001). Our society must adapt to changes in our environment whether these changes are sudden and disastrous such as a flood, or long term such as an aquifer drying out. Public participation in water management is beneficial because when citizens engage in management efforts there is greater cooperation in actions and a more inclusive understanding of an issue, permitting work toward a holistic solution (Mostert, 2003a). Priscoli (2004) asserts that we as a society have a moral obligation to provide citizens with water because water is the foundation for dignity, and we ought to allow citizens participate in water management planning, particularly those who face issues with access to water.

\subsection{Definitions}

Some key terms used in this research are perceptions, attitudes, and beliefs and views. Perceptions are used in the way described by Orne-Gliemann (2008), referring to an individual's, or group's, idea of water management, specifically the "practices, territories and organizations". Specifically in this research, a participant can perceive 
water as a human right, commodity, private resource, public resource and/or a natural resource. A human right is often defined as the right to freedom from abuse (negative right) and the right to basic human needs (positive right); everyone has the right to certain things, such as the right to education ("What are human rights?," 2012). A commodity refers to something that can be bought or sold (Webster, 2006). Public and private resources refer to any resource used by humans, having either universal ownership or personal ownership, respectively (Mankiw, 2011). A natural resource broadly refers to raw materials occurring in nature that are used for production and/or consumption ("Natural Resource," 2005). Attitudes, as used in this paper, refer to a position on a certain topic that is individual, but can be shared by various individuals (Heidmets \& Raudsepp, 2001). Beliefs and views are used interchangeably to mean the verbal announcements that reveal an individual's attitude toward a subject (Heidmets \& Raudsepp, 2001).

\subsection{Literature Review}

Public input can contribute to managing uncertainty when it comes to water management (Newig, Pahl Wostl, \& Sigel, 2005), and while it is known that public participation is not always easy to achieve, it is worth the effort (Jonsson, 2005; Webler \& Tuler, 2001). A paper written by Griffin in 1999 comments that there is a paradigm shift occurring in which natural resources management is shifting from a hierarchical management system to a more citizen involved bottom up approach. According to Griffin (1999), public interest in natural resources instigated greater involvement, and in 1970 the National Environmental Policy Act enshrined public participation in natural resources management. Fourteen years after Griffin's article, there have been a number of studies that have researched the role, the efficacy and the effect of public participation in water management. Adaptive management is now a commonly discussed topic (Pahl-Wostl, Jeffrey, Isendahl, \& Brugnach, 2011; Sefton \& Sharp, 2007).

Increasingly there is more public participation in water management. For example, in China, along with the government's strong presence in the water sector, public participation is encouraged and is growing (Gleick, 2008). As well, the European Water Framework Directive (WFD) is the key directive for water management in the European Union; according to Mostert (2003b) the input and participation of the public is critical for the WFD. Moreover, public engagement contributes to a more open and integrated governance, which leads to increased public acceptance of new policies, as well as enhanced appreciation and awareness of water issues. And finally, Mostert (2003a) asserts that public participation contributes not only to managing water, but to researching water management. In the Mediterranean, collaboration and cooperation contributes greatly to water management in shared riparian zones; Scoullos (2012) concluded that cooperation in the sharing of water resources can mitigate conflict amongst the groups using the water and furthermore can contribute to sustainable use of the resource. Sefton and Sharp (2007) conducted interviews with citizens in the United Kingdom, investigating views on storm water management, and specifically looking at what the participants think about water. These are three specific examples from approximately 17000 studies on collaborative, integrative, and participatory water research globally in the past 20 years. There has been research on public perceptions and involvement in the management of storm water (Giacalone, Mobley, Sawyer, Witte, \& Eidson, 2010), drinking water (Jones et al., 2005), wastewater (Alexander, 2011; Evans \& Varma, 2009), watersheds (Chess, Hance, \& Gibson, 2000), Indigenous involvement in water planning (Baird et al., 2013; S. Jackson, Tan, \& Altman, 2009) and shared riparian zones (Scoullos, 2012). There are also many forums and meetings that involve stakeholders, such as the Indigenous Fresh Water Planning Forum in Canberra, Australia (S. Jackson, et al., 2009).

The existing research used a variety of methods to collect information from the public, including surveys, community meetings, workshops, focus groups and others. The methods used are meant to engage the public in water management in order to gain insight from the public on local water management issues. Furthermore, some research suggests that not only do researchers and those involved in water management desire public participation, because participation improves water management in many aspects (Mostert, 2003a) but citizens themselves endorse public participation (Warriner, Madden, McSpurren, \& Lukasik, 1996).

Most of this research has been completed in water scarce regions or regions that are prone to water issues. There is significantly less investigation on water management in Canada. After studying consumers' perceptions of drinking water quality in Canada, Dupont (2005) argues that the use of integrated water resources management similar to that used in the United Kingdom will benefit Canada. One example of novel research on public input into water management is a study by Warriner et al. (1996) who investigated public perceptions and ideas in managing the Grand River watershed. The primary source of information for public attitudes on water in Canada is the Royal Bank of Canada Water Attitudes survey that collects perceptions and behaviours regarding water use and water management ("2012 RBC Canadian Water Attitudes Survey," 2012). This survey is used to provide the public perspective but does not engage the public on their ideas about water management. Previous work by 
Noga and Wolbring reveal that there are many different perceptions of water and different ideas about how water should be consumed and managed. The differences in these results were found to be related to how each participant perceived water (i.e. whether it is a human right, commodity, public, private, or natural resource) (Noga \& Wolbring, 2013). Further research would be beneficial for understanding the views of the public on water management in Canada. Research on water management should include both experts and stakeholders, and ought to begin with identifying the issues stakeholders consider merit investigation (Rinaudo \& Garin, 2005).

Calgary's Water Efficiency Plan includes involving the public through education programs, focus groups and pilot studies with interested parties, and an annual survey of citizen's behaviour and attitudes toward water conservation. The implementation plan includes goals such as "Lead by example" and "Changing behaviours (education campaigns or outreach)" (Water Efficiency Plan: 30-in-30, by 2033, 2005). The City's engage! Policy acknowledges the contribution the public can make to decision making processes and commits to including the public in decision making (engage! Policy Statement, 2004). A part of Calgary's Water Efficiency Plan is devoted to engaging interested stakeholders and communities (Water Efficiency Plan: 30-in-30, by 2033, 2005). Based on the literature that discusses the importance of public involvement in decision making processes, this is a positive step toward achieving the goals of reducing water use and improving efficiency. The next step is to begin to engage more citizens and to increase awareness about this initiative for the general public.

It is known that different academic disciplines, or tribes, have different ways of thinking and problem solving (Becher, 1994; Becher \& Trowler, 2001). However, the use of different academic programs for comparison is not a common research area. One example is a study that looked at the risk perceptions of different technologies of students from different academic disciplines; the study found there was a variance in risk perception amongst the different academic disciplines (Weisenfeld \& Ott, 2011). This is an area of research which should be expanded on.

\subsection{Research Question and Aims}

The research question is: What are the views of University of Calgary students in Engineering, Environmental Science, Medical Science, and Economics on water management and how do they correspond to the participants' perception of water? The specific aims used to address this question are: 1) what are the views of University of Calgary students in Engineering, Medical Science, Environmental Science and Economics on water management in Calgary; 2) do different academic backgrounds lead to different views; and 3) whether their views correspond to their perceptions of water?

The structure of this paper is based on these aims. After discussing the methods used in this research the results section is organized to demonstrate the findings for each of the aims separately. The discussion that follows shows how the results of each aim were related and offers the implications for policy. The conclusion provides a summary of the paper and insight into the next steps.

\section{Methods}

\subsection{Qualitative Research}

Focus groups were conducted to collect qualitative information based on open-ended questions as perceptions are best understood through a participant's own words (Conley \& Moote, 2003). Furthermore, qualitative research provides in-depth insight into the research question, allowing for the data to provide its own rich description of the results. There was no preconceived hypothesis. The purpose of the focus groups was to generate a discussion; focus groups allow participants to co-construct their ideas and build on each other's input (Wutich, Lant, White, Larson, \& Gartin, 2010). Focus groups were comprised of individuals in the same program so that they had the same academic background and were able to understand and expand on ideas discussed (Pahl-Wostl, et al., 2011). Furthermore, addressing the opinions of different interested stakeholders makes it is easier to see differences in ideas and where there may be differences in opinion (Janssen, Goosen, \& Omtzigt, 2006).

\subsection{Water Security Framework}

Water security means having a constant supply of clean water contributing to holistic human health and production of goods (Grey \& Sadoff, 2007). Water security is emerging as a critical issue, recognized by the Millennium Development Goals ("Millennium Development Goals Report 2013," 2013) and naming 2005-2015 the International Decade for Action 'Water for Life'. Water security in water management is critical for addressing security issues, particularly during this time of global development (Grey \& Sadoff, 2007). Throughout collecting, analyzing and writing, a water security lens was used to view the data. This means that throughout the research process, the findings were viewed with consideration to water quality and quantity, as 
well as any ideas within those, such as accessibility and affordability. The use of a framework provides the researcher with a lens in which to understand the data (Pahl-Wostl, et al., 2011), allowing the researcher to consider how the participants view management in relation to water security.

\subsection{Participants}

Participants were University of Calgary students from one of the following academic backgrounds: Engineering (ENG), Medical Science (MDSC), Environmental Science (ENSC), and Economics (ECON). These were chosen based on the idea that students from these faculties will think differently and have different views (Pahl-Wostl, et al., 2011). From now on the participants will be referred to as students. Students had to be from one of the four academic backgrounds chosen and attending school in either the Fall 2013 or Winter 2014 semester. The students participated in the focus groups with peers in the same field of study which allowed the researcher to more easily compare and contrast data within the groups, as well as amongst the groups. Co-workers of the researcher were excluded, as they had more biased background knowledge on the subject having been exposed to the researcher's previous work on water issues.

\subsection{Recruitment}

The students were recruited using purposive snowball sampling. Purposive sampling is a method used to gather participants who are from a certain group that has particular knowledge (Tongco, 2007). In this study this meant that the students were selected based on their program of study. Snowball sampling was employed, meaning that personal contacts of the researcher, other than co-workers, were asked to participate and those students were asked to invite their peers in the same degree. This sampling is useful when gathering informants from a network (Noy, 2008), the network in this case being the program the students were in.

The recruitment process was not targeted to students who had background knowledge in water management or water issues generally, but rather to students from different fields of study independent of whether they were or were not aware of the water issues faced in Calgary. This provided perceptions and thoughts on water management from a range of backgrounds including thoughts from those who had little or no previous knowledge on water management.

\subsection{Data Collection}

The focus groups took between 40-95 minutes to complete and were held in the area of campus where the students attend classes offered in their program. All of the aspects covered in the focus group questions were designed to collect holistic data on personal views of what should be included in a water policy and how actions should be implemented (Appendix A). The questions were pilot tested with other students with those results excluded. The focus groups were audio recorded and notes were taken by the researcher for thoughts or ideas.

\subsection{Data Analysis}

The audio recording was transcribed to text verbatim using Poland's method of rigor (Poland, 1995); this means every 'like', 'umm' and 'you know' spoken was included in the transcription, as well as laughing. Body language was not transcribed because it was not relevant to this research.

After transcription the texts were analyzed using an inductive and iterative coding technique, meaning that the researcher read the text and highlighted codes that emerged that identified themes that occurred in the discussion. ATLAS.ti $\odot$, a qualitative data analysis software (CAQDAS)(Koenig, 2004; MacMillan, 2005) was used to create themes using the coding tool and attach these codes to certain quotes in the text. The text was read continuously, re-reading for new codes as they appeared until saturation occurred, meaning no new data were becoming apparent to the researcher (Glaser \& Strauss, 1967). To improve trustworthiness during data analysis, the transcripts were read and coded separately by both the supervisor and the student; this improved validity through triangulation of researchers, meaning there are multiple views identifying the major and minor themes in the data (Creswell, 2013; Creswell \& Miller, 2000). By reading through all of the text continuously until no new themes are apparent the coding strategy was also iterative. Themes indicate the overall content of the discussion.

\section{Results}

Following the demographic results, the results are presented according to the three aims of the study; in the first section, the themes covering water management evident from the focus groups sessions are reported. The second section outlines differences and commonalities of student views based on their academic background. Finally, the third section presents results on how students' views on water management correspond to their perceptions of water. 


\subsection{Demographics}

A total of 37 students participated in 12 focus groups with three groups from each program: eight Engineering (ENG) students, 11 Medical Science (MDSC) students, nine Environmental Science (ENSC) students and nine Economics (ECON) students (Appendix B, Table 1). The only inclusion criteria was the program the students were in, therefore the year of study, specialization, major, or minor, and gender was not included.

\subsection{Aim One: Views of Students on Water Management in Calgary}

Using the water security framework as a lens the views of students revealed 74 relevant codes, which were collapsed into eight themes (for quantitative data see Table 2). Water security encompasses the protection of clean water sources, and some themes were directly linked to this, while other themes were related to water security through people and society and through policy management.

\subsubsection{Things to Address in a Water Policy for Calgary}

The following codes and themes came up in the question about what the focus, or focuses, of a water policy for Calgary should be (question 2, Appendix A), as well as throughout the discussion.

\subsubsection{Water Quality}

The discussion about water quality was very straightforward: it is important because it is necessary for life. Some groups were more concerned about Calgary's water quality than others, for example "I don't think the quality of water is any concern in Calgary" (ENG student). But those groups still acknowledged that water quality is important.

Water was acknowledged as either clean water or "Bottled water". When students were discussing drinking water, it was often referred to as clean water. Bottled water was discussed mostly in terms of ownership, meaning that students viewed bottled water as privatized or a commodity.

\subsubsection{Price of Water}

The price of water was seen as an important component to be included in the water policy. In terms of costs faced by individuals, such as taxes and usage fees, the codes were "Affordability", "Price of water", "Flat rate", "Metered rate", and "Willingness to pay". Based on a question about the metered rate that Calgary is currently switching to, all students agreed that the metered rate was far better than the flat rate (question 6, Appendix A). However, there was contention in this discussion about whether the price per cubic meter consumption should be increased or decreased: while two of the three ENSC groups believed that the price should be increased to better reflect the value of water and to decrease consumption, an ECON group and a MDSC group were more in favour of making water more affordable if not free. This conversation reflected some of the discussion about affordability. Other times affordability was mentioned as an important focus of the policy, such as "price [...]allocates who gets water, so it's a big part of deciding where water goes, how much is used uhh based on affordability" (ECON student) (Note 1)

Willingness to pay was discussed both in terms of industry and individuals being willing to pay more for water, one ECON student argued that:

"oil is only, it's a- it's a non-renewable resource only found in certain parts of the world and umm suppliers are gonna be willing to go to whatever extent they have to to make a dollar and if that's at the expense of our water system even if they have to pay a high price for it they're going to be willing to do that"

While the price was contended the importance of deciding on a price was common.

\subsubsection{Access and Security}

The two codes given to discussion about access to water are "Accessibility" and "Water availability". Eight of the 12 groups explicitly mentioned accessibility as being an important component of the policy, and one of the groups that did not say accessibility mentioned availability as an important aspect to include in the policy. Sometimes the students specifically indicated access to 'clean' water.

Water security was only discussed by five groups, and only two of those groups considered it a factor that should be addressed in the water policy. The discussion of security amongst the five groups revealed the students think that in terms of both quality and availability.

\subsubsection{Preparedness}

Preparedness was typically about the budget and addressing issues such as pollution and natural disasters. One 
student articulated that there should be "leniency when it comes to budget" (ENG student). Being prepared for running out of fossil fuels was also mentioned by one MDSC student.

Specifically related to natural disasters, "Calgary 2013 Flood" was coded whenever a student mentioned the flood in Calgary in the summer of 2013. Five groups mentioned it a total of ten times.

\subsubsection{Sustainability}

Sustainable use was discussed regularly as important not only to address in the water policy, but to consider in all aspects of water management and environmental management. In particular, considering the future and sustainability together:

"we're running out of clean water like we're running out of fresh water and if we don't start looking at sustainable ways of cleaning that water we might be in trouble not only will like animals and nature will be in trouble but humans will too, so...it's something that needs to happen sooner or later, and let's just do it sooner" (ENG student)

\subsubsection{Treatment}

Treatment was not mentioned in the first question as an important aspect to address in a policy for Calgary, presumably because the students thought that: Calgary has one of the best water treatment facilities uhh in the world" (ECON student). However, during the discussion treatment was addressed as being an important aspect of water management.

\subsubsection{Protection}

The codes "Protect water", "Protect environment", "Increase environmental protection", "Pollution" and "Prevent waste" were discussed as being a critical aspect that should be considered. Pollution was discussed both in terms of individual pollution and industry pollution, sometimes as one being more important than the other. One ENG student suggested treating different kinds of pollution differently, and having different legislation for each. The groups recognized the importance of addressing protection in a water policy, such as: "the protection of ecosystems and water is umm the prime directive" (ENSC student).

\subsubsection{Reduce Consumption}

"Conservation", "Sustainability", and "Decrease consumption" were the codes included in reducing consumption, which was mentioned as being important to include in the water policy and was discussed throughout the focus groups. Much of the discussion revolved around reducing current water consumption in Calgary, not only just in the question about consumption but throughout the focus groups. For example, an ECON student suggested that "the best way to try and restrict them is how number three said is with the price if all of a sudden if after your restriction your water price jumps to twenty dollars a litre you're gonna be really smart about that". There was however some skepticism to this discussion, such as one MDSC student pointing out that "this whole downstream reducing use and like that's a good idea and everything but we're gonna use that method because it is obviously profitable right".

\subsubsection{Awareness}

Only one MDSC group and one ENSC group mentioned awareness in the first question about what to include in the policy. However, awareness was brought up frequently during the question about consumption. The following dialogue demonstrates the ideas awareness and engagement that were discussed:

“\#2 But the how do we increase umm public participation and like their willingness to know

\#4 Well like the funding could probably go towards some education programs, like public awareness programs" (ENSC students)

Having the public understand water issues was coded as "Media awareness" and "Awareness". Increasing awareness in order to decrease consumption was discussed as beneficial, in particular using media to increase awareness. In addition to awareness, citizen engagement and education were discussed as the next step to improving water management and reducing consumption.

Sometimes the value of water external to the price, the monetary value, was discussed as something that should be made known to the public. These included things such as esthetic value as well as more abstract ideas such as "we're ninety percent water, we have to have it so I guess the value I guess it's really tough to say" (ENG student). Others stated that the value of water is based on how essential it is to life. 


\subsubsection{Efficiency}

Efficiency was mentioned only once explicitly in the question about the focus of the water policy, by an ENSC group, however efficiency in management and using efficient low-flow technology was discussed often as something that should be in the policy. There was one interesting idea that was thought of in two of the three ENSC groups when it came to addressing efficiency, which was allocating water in times of scarcity based on proving that "you still need this and that you're being as efficient as possible with your usage" (ENSC student).

\subsubsection{The Budget for a Water Management in Calgary}

The codes within the discussion about the budget include "Money for water", "Costs", "Funding", and "Investment". The monetary inputs to managing water were discussed primarily in regard to the budget for treatment and protection. In response to the question about the budget for water treatment and for environmental protection (question 4, Appendix A), ten groups agreed that the current budget for water treatment is fine as it is. Funding and investment were mostly related to developing new high efficiency technologies (THIS NEEDS TO BE DELETED more information in section 11.1 Solutions). The costs discussed throughout the groups were about making changes and implementing these new technologies.

\subsubsection{Who Is Involved in Water Management in Calgary}

The different sectors and types of inputs were as follows: "Expert voice", "Academic voice", "Public voice", "Private sector", "Government", and "Neutral party". All of these groups were mentioned in terms of both implementation and management of the policy, and evaluation of the policy. In particular, input from the public and from scientists was discussed as very important. The government was also discussed in relation to current policies and actions being taken:

"the oil and gas companies are following what the regulations are so, if the government is allowing them to use that much water then maybe the government says to say, needs to say uhh nope stop that (laughs)" (ENSC student)

Within the discussion about involvement students discussed: "Multi-level", "Multi-sectoral", "Accountability", and "Responsibility". The idea of a multi-sectoral management team, meaning having a variety of all of the sectors discussed, was a common idea when asked about who should be in charge of the policy (question 3, Appendix A), and who should be in charge of evaluating the policy (question 11, Appendix A). Multi-level also came up but not as often. Both accountability and responsibility, in terms of the policy being unbiased, were discussed throughout the focus groups.

\subsubsection{How to Achieve Changes in Water Management in Calgary}

The idea of creating change was coded by "Change habits", "Change perspective" and "Change practice". Changing habits means changing individual actions such as taking shorter showers and "change our lifestyle a little bit stop eating all those chicken Mcnuggets" (ENSC student).

Changing habits was discussed in occurrence with decreasing consumption. Changing the individual's perspective was also discussed, predominantly as a long term solution:

"there's been like a long standing idea in umm environmental management that you give people enough information and they'll start changing their habits so umm, you change their framework or you change the thoughts and you change the habit but I think what's starting to come to light is that if you start changing people's habits, their thought process starts to change" (ENSC student)

Changing habits can be related to the discussion about lifestyle, which was specifically mentioned as having an impact on water consumption, especially when asked about Calgary's current level of consumption, and comparing it to other countries' consumption levels (question 5, Appendix A). Most of the students who mentioned lifestyle discussed it as something that should not be changed, such as one MDSC student stating that "it's hard to say just for water consumption to change your whole lifestyle right".

Changing perspective was also seen as a way to start getting the public on board with new regulations:

“it's the same as, think of smoking, if you would've told people twenty years ago you can't smoke in your own house, I mean, how would that have gone, but since they made it illegal to smoke in public areas, well look what's happened, it's really caught on, a lot of people quit anyways right so yea, I really like that idea, if you did it in a public setting where people could adapt to it "cause they had to it might even change their private decisions right, private choice" (MDSC student)

Changing practice is about industry and business practice, such as suggesting that the industry "get new 
technologies that are more water conservation based or they won't frack and either way is a win win" (ECON student). Many of the changes were for the purpose of reducing water consumption either by reducing consumption, being sustainable or conserving water.

The ways to achieve this change include "Awareness", "Incentive", "Penalties", "Policing", "Regulations" and "Restriction". The extent of the invasiveness of the methods ranged from passive interventions, such as "get people to know how much water they use and where they're using most of it" (ENG student). As well, legal enforcements were suggested:

"it has to be sort of a forced habit change and then in a few years people will start to think differently, so for example if it's made illegal to actually water your lawn between nine am and five pm so you avoid the hottest parts of the day, umm, people will hate it at first, but in a few years it'll be like you'll see your neighbour watering at two pm and they'll be called out on it and so it's no longer a recommendation, it's just how things work in Calgary" (ENSC student)

Other ideas for promoting change using legal action were a bit simpler, such as "make it illegal to plant new lawns that are not native grasses" (ENSC student). Conversely, positive reinforcements were suggested, such as income incentives. These methods for change were discussed and debated, particularly the impact of any intervention on the public.

Some groups did not see change as necessary, and discussed keeping the status quo, having no restrictions, and argued that it is out of our hands. This was related to water consumption levels, the budget for water treatment and the use of water for hydraulic fracturing. The students suggested "being in our position and our water quality and supply and everything we're in no real concern about strictly decreasing the water all of a sudden" (ENG student). And others ideas about letting the industry work as it always has.

\subsubsection{Evaluation of Water Management in Calgary}

Setting goals and monitoring were the methods of evaluation discussed, such as "you need inspectors and you need random checks and you know like quality control" (ENG student) and "The closer we get to our goal, the, that's how we measure how, good the quality" (ENG student).

In terms of the students mentioning how they think water management is doing so far, the codes were: "On the right track", "Room for improvement", "Calgary rocks" and "Canada rocks". On the right track and room for improvement were both used in a positive way, starting with appreciating what is being done so far and then mentioning that there is still work to be done, "we're on the right path, uhh declining our water use per person but we do really need to make a conscious effort just in our daily lives to use less water" (ECON student).

Ideas about why Calgary rocks in regards to water management included "Calgary has a very good waste water treatment plant as it stands right now like our water's quite clean" (ENSC student).

\subsubsection{Challenges Faced in Water Management in Calgary}

The students recognized a variety of challenges related to water management, including:

1) Trying to get the public on board with decreasing consumption, for example, "it would be tricky to try to... influence people to change the way they consume water" (ENG student)

2) Creating the appropriate group to manage the water policy, and finding ways to reduce consumption,

"just simply putting in some sort of clause that in all new houses they to be fitted or fitted with really high efficiency everything uhh little things you can introduce obviously it can be tough to enforce because somebody might even still if they have a high efficiency shower have like a three hour long hot shower in the morning" (ENG student)

3) Finding a way to address the high consumption of water in the oil and gas industry and keep the economy going, meaning "balancing both problems at once" (MDSC student)

4) Changing the public opinion in general and 5) implementing a gray water system. All of these challenges were discussed, although the ENG groups did not recognize any of these ideas as being a challenge.

\subsection{Aim Two: Do different Academic Backgrounds Lead to Different Views?}

Using the codes and themes discussed, this section will lay out the similarities and differences between the student groups in how they discussed the codes and themes. To start, all the student groups talked equally about accessibility, consumption and sustainability. In general, the ENSC students discussed activism and making changes the most, ENSC and ECON students discussed monetary aspects the most, ENSC and MDSC deliberated the most on evaluation, and the ENG students offered the most solutions (for quantitative data see 
Appendix B, Table 2). The amount of discussion in each student group about each topic is often due to the amount of time spent on the corresponding question (Appendix A).

\subsubsection{Environmental Science}

The ENSC students were in favour of promoting public awareness and engagement in water management, and changing any wasteful habits, by many different means. For example, one student discussed engaging citizens so that they are stewards of the environment. As well, ENSC students discussed the importance of the involvement of scientists, meaning academics and experts, in both the creation and implementation of a water policy as well as the evaluation. The students agreed on involving the public in the process, but discussed that the issues maintain a foundation of scientific research.

The ENSC students did not once mention leaving things the way they are, and most often discussed changes in habits, perspective and practice. Monitoring was also discussed as being particularly important, not only during evaluation of the policy, but on a consistent basis of monitoring water in Calgary. Similarly, water quality was the third most common topic, below awareness and decrease consumption. One phrase that the ENSC students did not use is 'clean water'.

\subsubsection{Medical Science}

Making changes was the most frequently discussed theme by the MDSC students, in relation to decreasing consumption. In particular, the students talked about the need to change habits of citizens in order to reduce consumption. Methods for change were also discussed, but mostly in terms of incentives, and less so for regulations, penalties and restrictions. This is because the students agreed that "if you start putting restrictions on things like people [with emphasis] freak out" and so incentives are a better way to change perspectives and behaviour. The "oil and gas" (please delete quotation marks) sector was discussed by the MDSC group more often compared to any other group.

\subsubsection{Economics}

Decreasing consumption was the most commonly discussed idea, and was mentioned throughout the discussion in the focus groups, including when discussing the price of water, which was the second most commonly discussed topic. The price of water was discussed as a solution to decreasing consumption and increasing protection, such as "I think if you have a set goal of how much water we can draw out of our system per year overall, I think you can find a price, you should be able to find a price that gets you near that" and "some of that could be moved towards water protection".

Although the ECON students discussed monetary aspects, the discussion was concentrated on individual fees. Government involvement was the third most frequently deliberated idea, discussing that:

"wouldn't it be like a government's responsibility to be, to you know uhh being a superior body that controls everything else I don't know I'm thinking shouldn't they be responsible for providing clean access to water?"

While all the other groups thought about and discussed the impact that lifestyle has on consumption, the ECON groups did not mention this, and in fact only discussed the impact of the individual twice. Preparedness was also not discussed, nor was renewable energy or the flood. The overarching concept of monetary ideas and values were discussed the most by the ECON students.

\subsubsection{Engineering}

The budget was the most commonly deliberated idea throughout the ENG students. Increasing money for water, funding for research and development, and switching to the metered rate were the most recurrently discussed ideas; neither affordability nor investment was discussed. Compared to other groups, the ENG students most often discussed technology and research development, for example "I do feel that we should fund education, especially engineering and science".

This translated into the students talking about many different solutions, with ideas about reducing consumption both at an individual and industry level. Water quality also often came up in the discussion. The students were the most excited about what Calgary is already doing, and discussed the positive aspects of Calgary's waste water treatment system. The ENG students agreed on opposition to restrictions on water usage.

\subsubsection{Connection between Engineering and Environmental Science}

The ENG students and the ENSC students had many similarities in the ideas discussed. The similar discussion included ideas about awareness, downstream effects, pollution, treatment, the future, water infrastructure, water 
quality, and efficiency. For example the discussion of downstream effects:

"You know like people affected by the downstream effects of a waste water treatment plant, things like that, are actually accounted for" (ENG student)

"if you put pollutants back in and it's downstream of you it's not a problem for you anymore but people downstream it's effecting a lot now too so they have to do more treatments" (ENSC student)

Another example is the ideas about awareness, and tying it into the cost of water:

"Also, people spend less on water like on their water bill if they use less water so that's something you could advertise" (ENG student)

"I think we should pay more for water and that all water should be metered because then people have a better idea of actually what they're using" (ENSC student)

They also both discussed money for water and the money used in the municipal budget more often than the other two groups. Both groups also talked the most about activism and about evaluation of the policy.

\subsubsection{Connection between Environmental Science and Medical Science}

ENSC students and MDSC students also had many similarities. Both groups discussed incentives more than double the amount of the other two groups. These two groups also discussed the involvement of different groups and entities the most, and the importance of accountable, responsible and unbiased (neutral) perspectives. Furthermore, both mutually agreed on having a neutral party be involved in managing and evaluating. Only these two groups discussed water security, and suggested allocating water to industry based on the production of that industry. The ideas about allocation based on need for production were as follows:

"they need to show that their allocation is still current that let's say farmer one can demonstrate that yes they still need [...] that allocation and they can specific this is how we use it" (ENSC student)

"if you have one that's like you know farming for crops or something that they need the, like rather than someone who's doing something else with the water I mean I might prioritize" (MDSC student)

Although the MDSC students' of discussion oil and gas is the third most common topic in the student group, in total the ENSC students discuss the topic of the energy sector more often comparatively.

\subsubsection{Connection between Environmental Science and Economics}

The only common idea between ENSC students and ECON students is the more common discussion of the value of water compared to the other two groups. To compare two of the quotes:

"I don't think there's a proper value placed on, on water because we're so fortunate in that we have, it seems like unlimited resources" (ENSC student)

"if you look at the amount of people who shower the amount we take it for granted just taps left running and stuff like that" (ECON student)

\subsubsection{Connection between Economics and Medical Science}

The ECON students and the MDSC students had two similarities. Both discussed the idea of water being affordable, and there was even some discussion about water being free. As well, both seemed to be able to agree that water either is or could be a commodity:

"Yea, it's definitely become a commodity over the last couple years especially with bottled water" (ECON student)

"you could think of like bottled water as a commodity" (MDSC student)

\subsubsection{Connection between Economics and Engineering}

The ECON students and ENG students discussed human health the most, and the importance of water for human health:

"we all depend on water umm for survival" (ECON student)

"we're ninety percent water, we have to have it" (ENG student)

As well, the two groups discussed increasing environmental protection, particularly in terms of increasing the budget for environmental protection:

"reallocate the other uhh the other surplus to umm other things we might want to consider environmental" (ECON student) 
"Add a little bit more to the environmental [budget]" (ENG student)

No other comparisons were found amongst the different groups.

\subsection{Aim Three: Whether Views on Water Management Correspond to Perceptions of Water}

When trying to understand people's ideas concerning water use, it is useful to first understand how people perceive their water $(\mathrm{Hu}, 2011)$. Perceptions of water reveal the way water is understood, which is intertwined with the way water is used. Further, perceptions will determine ideas about ownership and responsibility for water management (Dupont, 2005). The perceptions offered in the first question were: human right, natural resource, private resource, public resource and commodity. All of the student groups mentioned that water is a public resource and discussed it as such in the focus groups. Eleven of the 12 groups acknowledged water as also being a natural resource, with the exception of the one ENSC group; however even this group discussed it as a natural resource during the rest of the discussion, in comments such as: "we're having less and less places to draw from, water from and lakes are a great reservoir for them" (ENSC student).

Five of the groups explicitly stated that water is a commodity, two of which related it to the bottled water industry. On a few occasions the idea of water being a commodity was relayed in discussion such as:

"people who want perfect lawn can spend the extra amount of money better than you know some guy who doesn't even care about it paying for the other guys lawn, indirectly if you know what I mean" (ENG student)

The same occurred with water being explicitly mentioned as a human right at the beginning, and then not as much during the conversation. An exception to this was one MDSC group which did not discuss water as a human right in the beginning, but continued on to discuss and refer to it as a right later on in the focus group. And finally, water was only mentioned as possibly being a private resource by one ECON student group, with the stipulation that it would be a private resource if it was on privately owned land. Another group however suggested privatizing water when asked about who should be in charge of the water policy. In general, regardless of how water was mentioned at the beginning, it was mostly discussed as a natural resource or a public resource during the focus groups.

Other perceptions that were brought up and discussed were water as a basic need, limited resource, important resource and an unsustainable resource. The ECON students did not mention water as being a basic need, although all of the other groups did, especially the ENSC students. Water as a basic need was discussed as "we need water to survive, what's that thing, where it's you'll die faster without water than without food" (ENSC student).

All the groups discussed water as a limited resource, such as:

"running out of clean water like we're running out of fresh water and if we don't start looking at sustainable ways of cleaning that water we might be in trouble not only will like animals and nature will be in trouble" (ENG student)

It was mutually agreed that water is an important resource; one explanation of its importance is offered by an ECON student:

"water is used not just for drinking but for recreational purposes and also the esthetic value that uhh environmentalists always often place uhh so we should take that into consideration as well and that makes water even more important"

And finally, water was acknowledged as an unsustainable resource, although only discussed by the ENSC and MDSC groups, for example "if we keep doing what we're doing with it right now I think it's unsustainable resource, fresh water will be an unsustainable resource" (ENSC student).

\section{Discussion}

The discussion relates to the aims of the study and to water security. Furthermore, the findings are discussed with their utility for local water policy in mind. The final section of the discussion offers some key directives for policy makers based on the findings of this study.

\subsection{Aim One: Views of Students on Water Management in Calgary}

\subsubsection{Protecting Our Water Resources through Monetary}

Protection and reducing consumption are elements of water security (Grey \& Sadoff, 2007). Protection and reducing consumption were tied together with the budget and individual fees in relation to increasing protection and reducing consumption, respectively. Protection, including protecting water and the environment, were seen 
as important aspects that required ample funds. This led to ideas about increasing the overall environmental protection budget, as well as creating an emergency fund. Throughout the student groups it was agreed that:

"the metered rate is a better way to do it, not only, umm, so let's say like I get my bill at the end of the month and I own a house I can see oh this is how much water I used, this is how much I have to pay now because before if I'm just paying a flat rate it doesn't matter if I use no water or a hundred litres of water that kind of thing, and then also if you have incentives in place then people can see their decrease in consumption too, so it can ma- motivate people more" (ENSC student)

The students agreed that the metered rate would help in reducing consumption; this indicates that there is interest in reducing consumption, reflecting the general agreement that it is important for Calgary to make an effort to use less water.

Disagreement on the price of water was based on why the groups thought water should be affordable versus why it should have a higher price. Those who wanted water to be affordable seemed to think that a price would act as a barrier for those who would be unable to pay for water. If the students see the possibility that someone who could not afford water could consequently not receive water then likely the students do notDELETE see water as a human right that must be provided to everyone. The idea behind increasing the price of water is to reduce consumption and make citizens more aware of their current consumption habits. The priority was different amongst the groups.

\subsubsection{Involving Everyone in Water Management}

The multi-sectoral approach was commonly discussed, including the voice of scientists, the public and the government, and sometimes the private sector. This approach was discussed for both the creation and management of the policy and for evaluation of the policy. This contrasts with the study discussed previously (section: Literature Review) which conducted a survey and three case studies in Grand Cache, Ontario. In that study the participants were more accepting of government leading resource management and did not seem interested in participating in the decision making process (Warriner, et al., 1996). Comparing the study in Grande Cache to this research in Calgary, two different paradigms arise; while the students in Calgary see water management using the integrated, adaptive paradigm, the students in Grande Cache were using the prediction, control paradigm (Pahl-Wostl, et al., 2011). In this article outlining the two paradigms, Pahl-Wostl et al. (2011) argue that the adaptive model is a superior model because it recognizes the complexity of water management. Furthermore, the adaptive paradigm offers a more holistic approach (Pahl-Wostl, et al., 2011); holism was discussed during the focus groups as a solution to water management issues. Having an adaptive capacity in water management can contribute to protecting and securing water (Pahl-Wostl, et al., 2011). Although the groups often discussed involvement of the government, the multi-sectoral, sometimes multi-level approach was the agreed on approach.

Similarly, public involvement in terms of increasing awareness and engaging the public in water management and conservation activities was discoursed. Enhancing awareness of water consumption levels, pollution issues and ways to improve both were seen as solutions. Sefton and Sharp (2007), who looked at what people think about water in the United Kingdom, found that awareness was low because water was intrinsically involved in the participants everyday lives and so it was "beyond notice"; this notion of not consciously thinking about it was discussed in one of the focus groups "there's maybe some level of awareness most people are pretty comfortable knowing you know, we're Canada we have lots of fresh water and they don't really worry about it" (ECON student).

\subsubsection{Value-focused Thinking and Awareness}

Increasing the awareness about the value of water was also discussed, which can be related to value focused thinking, which involves using values as the root for an approach to public engagement in the decision making process. McDaniels et al. include the value-focused thinking approach when discussing their project on involving the public in water management by creating the Alouette River Stakeholder Committee (McDaniels, Gregory, \& Fields, 1999). In the focus groups, the ENSC and the ECON students discussed emphasising the value of water in order to make the public more interested in reducing their consumption. This is another element of adaptive management and water security (McDaniels, et al., 1999; Pahl-Wostl, et al., 2011).

The students acknowledged that water is not often a cognisant thought, but agreed that making it more apparent could contribute to reducing consumption. Comparing the discussion to the findings of the study in the UK, it was commonly agreed in both studies that water is important because without it we cannot survive (Sefton \& Sharp, 2007). 
It was agreed that lifestyle impacts consumption but whether it ought to be changed was disputed. This relates to whether the students see water conservation as a priority, or as an extra issue which is great but not necessary. Willingness to change a lifestyle for the purpose of conserving water could be further investigated to understand the level of difficulty in achieving public uptake of a policy.

Another concept that was to contribute to awareness is natural disasters, and specifically the Calgary Flood. When the students linked their knowledge about water management to what they know about the flood shows that the flood affected the students' awareness of water in Calgary. Many of the students were living in areas that were put on a boil water advisory, and thus experienced a threat to their own water security. In a study by Jonsson (2005), the participants said that the occurrence of a localized problem that affected them would cause them to get more involved; this may be the case for why students were aware of the issues, particularly in relation to natural disasters.

\subsubsection{Water Quality}

Although bottled water is often perceived as cleaner and of better quality (Doria, 2006), the students never once suggested that they believe that. In fact they often indicated that the tap water in Calgary is the best quality in the world, indicating positive sentiments about Calgary's water security. This could indicate that bottled water is becoming less popular in younger demographics, but also that the students are satisfied with the water quality in Calgary. This is a relatively unique finding, as many studies show that consumers prefer bottled water.

\subsubsection{Sustainability}

Recognising the importance of keeping water safe and secure for Calgary demonstrated that students think toward the next generation and have a forward looking view. It is possible that this concept is something that is taught within the university setting. The students discussed sustainability as keeping everything as it is for the future generations:

"we need to make the earth umm you know, leave it like you found or better than you found it and that's what we need to do although it is, seems kind of backwards that we're spending more on our water than we are on our police services um, I think that we're at a good level and we do our best to make sure that we're the earth in a good place" (ECON student)

\subsubsection{Change}

The idea of changing people's perspectives and habits again reflects the new adaptive management paradigm (Pahl-Wostl, et al., 2011). Changing perspectives requires that citizens begin to think more about the consequences of high consumption and pollution, and changing habits requires citizens to become more engaged in decreasing consumption. In some occasions the students discussed changing technologies rather than changing lifestyle, such as switching to low-flow toilets and showers heads. These ideas were related to regulations and restrictions, making it mandatory to implement low-flow technology. On the more passive side of change, awareness and incentives seemed to be a popular idea for influencing change. Awareness was often related to a change in perspective, and incentives to a change in habits. All of these ideas about change, whether the change is by enforcement or by enticement, reflect that the students are in favour of improving water use and securing water sources, and by involving the public in the process the students are using an adaptive management lens. Even for those who were not in favour of change, the idea of involving the public in water management was still apparent.

\subsubsection{Challenges}

The challenges recognized by the students showed that some students were aware of the struggles when trying to influence change, whether it is getting the public to be more thoughtful about their water use or trying to address the conflict between protecting the environment and developing the oil and gas industry. It was interesting to see that while some groups recognized these areas as challenges, other groups did not. In particular, one MDSC group discussed the difficulty in implementing a gray water system while other groups thought that it was already being done in Calgary. For policy makers, this may be an area for citizen and government interaction on how to overcome these identified challenges.

\subsubsection{Implications}

Based on the findings, there are a few key ideas that could be considered by policy makers. The overall support for reducing water consumption in Calgary is clear, as well as protecting water and maintaining high water quality. Yet many of the students were unaware of any current initiatives to reduce consumption and to decrease pollution and protect water in the environment. Considering that Calgary already has a Water Efficiency Plan 
that addresses reduction in consumption levels (Water Efficiency Plan: 30-in-30, by 2033, 2005), awareness about this plan should be increased, possibly through media. The City is not currently actively seeking public engagement; media such as Twitter and Facebook could help to recruit Calgarians, by making a page with interesting facts and information, and asking citizens to follow them on Twitter and like them on Facebook. There are other channels as well, such as ads in newspapers and having booths at popular local events, as well as targeting students specifically by providing facts and information about how to get involved through University listservs of specific programs and emails from program coordinators. The critical idea is that a selective approach is needed.

Additionally, education on water treatment, daily water consumption, and potential water issues that may impact Calgary could be integrated into the Plan, possibly in a school setting as suggested by the students. Considering that the students were in favour of increasing public involvement, education could be a good place to start. Thus, future policy should consider not only enhancing awareness about water use but also increasing awareness about actions being taken, such as advertising sales on rain barrels and indicating in stores that low-flow toilets are subsidized.

\subsection{Aim Two: Do Different Academic Backgrounds Lead to Different Views?}

An interesting anecdote from Pahl-Wostl et al. (2011) sets the stage for the differences in thinking amongst academic groups: "When an engineer analyzes a water stress situation he will most likely detect technical problems such as inefficient use of available technologies whereas a social scientist will perhaps see the problem as rooted in the perceptions of individuals and perhaps in a lack of awareness or concern about declining water resources". This shows that there are different ways of thinking, and these different ways of thinking will influence how water management is dealt with. The four student groups had differences and similarities that can be attributed to what is taught in their programs as well as the type of thinking that leads a person to be in each subject area.

\subsubsection{Other Backgrounds}

While this research focused on the academic backgrounds of the students, the students more often associated with other backgrounds, such as an agricultural background, working in oil and gas, having a parent who works in oil and gas, being from another country or province, being a gardener, or being a part of a student body. The students identified having these backgrounds as a way of explaining where they were coming from. Future research could further pursue these different perspectives.

\subsubsection{Engineering: Problem Solvers}

According to the Schulich School of Engineering webpage, the school emphasizes a foundation in research, innovation, and "international excellence" (http://schulich.ucalgary.ca/). Further, the website describes four key strategic areas, namely "student experience, research excellence, contemporary infrastructure and links to the community". The primary discussion in the ENG groups was about solutions, specifically research and development and technology. Sefton and Sharp (2007) found that participants have a "dependency on large-scale high-tech solutions" based on their discussion about water management, which is similar to what the ENG students were keen on. The students agreed on the importance of environmental protection and water quality and promoted what Calgary is already doing to address those topics, and furthermore were able to discuss ways to reduce consumption and protect the environment.

\subsubsection{Medical Science: Socially Conscious Thinkers}

According to the Faculty of Medicine Bachelor of Health Sciences webpage, the program supports research in all aspects of health, "from cell to society" and has students engage in interactive learning (http://medicine.ucalgary.ca/bhsc/program). The individual versus society, and equity were mostly discussed in the MDSC group; these are themes that are integrated into the Health Sciences discourse, so the discussion likely reflects the learned knowledge. Furthermore, the MDSC students discussed change, and many different methods of making that change that would suit the people. The students agreed that the best way to create a positive change is to offer monetary motivation. The MDSC students seemed to have a strong grasp of how to think through and implement issues of society.

\subsubsection{Environmental Science: Environmental Stewards}

According to the ENSC web page, a Bachelor of Science in ENSC offers "a multi-disciplinary approach to understanding environmental issues facing society" (http://www.ucalgary.ca/ensc/). Larson and Lach (2008) found that the more concerned a person is about water issues, the more likely they are to be actively involved; the ENSC students were clearly the most concerned and were the most in favour of engaging the public in water 
management. While a MDSC student commented that "I'm not sure whether citizens would be interested in water management and environmental protection I mean that's kind of a boring topic" the ENSC students were keen on activism.

\subsubsection{Economics: Economists}

According to the ECON web page, the department is research oriented, specializing in a range of fields including "Energy, Environmental and Natural Resource Management; Behavioral and Experimental Economics; Health; Industrial Organization; International Trade; Money and Banking and Public Finance" (http://econ.ucalgary.ca/). The ECON students discussed the idea about decreasing consumption by way of regulating the price. The students seemed the most comfortable with deliberating the budget and price of water, and agreed that individual fees that reflect the value of water were the way to go. This group also agreed that the government should be the leader of any group involved in water management; this is likely a way of thinking learned in the degree, based on the economic market being overseen by the government.

\subsubsection{Comparing the Student Groups}

The similarities between the ENSC students and the ENG students are extensive; both groups agree about the importance of environmental protection, water quality, and thinking about the future. Both groups discussed addressing these aspects, although the ENG students focused more on technology while the ENSC students focused on citizen engagement. One can speculate that reasons for this are the nature of addressing these issues within the respective programs, as well as possibly the more hands on application of knowledge found in their academic studies.

The similarities between MDSC and ENSC are also likely due to training in the program, but more so in the thinking process. Both groups discussed having a neutral party involved, which is likely because both programs address academic research and therefore learn about bias in research. As well, both groups deliberated on issues with the oil and gas and energy sector; however this is more likely due to the background of MDSC students as three of them mentioned having family members who work in oil and gas, while the ENSC students are exposed to information about the industry within their program of study.

The ENSC students and the ECON students both discussed the value of water, likely due to their training to recognize that resources have a value external other than monetary.

The explicit discussion of water being related to human health, and the need to increase environmental protection in the ECON and ENG groups was initially surprising considering one would expect the MDSC students to discuss human health and ENSC students to discuss increasing environmental protection. However, in the same way that Sefton and Sharp (2007) found that participants were not thinking about water because it is entrenched in their everyday lives, the students who fully understand water to be a determinant of health, or water to be a resource that needs to be protected, may not think to discuss that, as it is "beyond notice" to them.

\subsubsection{Implications for the University of Calgary and Other Post-Secondary Institutions}

The connections between the different student groups may indicate opportunities for multi-disciplinary collaboration, not only for the discussion of water management but on a variety of topics that could benefit from different perspectives. Encouraging and providing more opportunity for different programs to join forces could be a beneficial step for any post-secondary institution. This might involve multi-disciplinary research symposiums, offering special topics classes that count for credit for various faculties, and creating multi-disciplinary research teams with funding opportunities. The students in this research seemed keen on using a multi-disciplinary approach, which may indicate that there could be ample uptake of this approach on behalf of the students. Another critical component of uptake is finding funding for this particular research area, which is the responsibility of the institution to pursue. Incorporating a multi-disciplinary approach into post-secondary curriculums would provide a structured approach to enhancing collaboration amongst students.

In terms of water security and water management, the University of Calgary could provide more awareness about water issues, and integrate more information into university courses. This could encourage students to become more involved in water management, and to get involved in Calgary's Water Efficiency Plan (Water Efficiency Plan: 30-in-30, by 2033, 2005).

\subsection{Aim Three: Whether the Students'Views on Water Management Correspond to Their Perceptions of Water}

Sefton and Sharp (2007), who conducted interviews in the United Kingdom looking at what the participants thought about water found that the participants did not associate water with the environment; this does not coincide with the discourse amongst the students who acknowledged water as a natural resource. The reason for 
the students agreeing that water is both a natural resource and a public resource is likely because of the encompassing manner of the terms; water is used by the public and water is natural, as confirmed during the discussion, therefore it is a public resource and a natural resource. Although the students were not asked to define commodity, based on the discussion of the groups who accredited water as such, it is clear that they see a commodity as something that can be sold to a consumer to make a profit. This is illustrated when the participants connected water as a commodity to the bottled water industry. It is possible that those who did not agree that water is a commodity have a different definition, but also that the participants simply did not consider that water could be a commodity because no one makes a profit on tap water. The same possibility could be for those who did not see water as a human right. It is possible that the one group that did not explicitly say water is a human right but later discussed it as such did not understand the definition of human right according to the United Nations. Others who did see it as a human right, but did not discuss it as such may be unclear on the implications of water being a human right. And those who never acknowledged water as a human right either implicitly or explicitly may have thought that water is not a human right. None of the groups thought water was a private resource, other than if it was on private land, and the idea of privatizing water was not popular. This could be out of fear that making water a private resource means that ownership is taken away from the public, similar to the idea discussed in the focus groups that private industry is only in it for profit which could lead to exclusion and exploitation. Water being a basic need is something taught to students in elementary school, and therefore it is intrinsic knowledge. However, the idea that water is limited, unsustainable, and important is a learned belief that is just coming into the public discourse, and is not yet discussed in the academic discourse. Yet these ideas are clearly on the minds of the participants, likely indicating the future of how society views water.

\subsubsection{Implications}

Canada was the only country to vote against a draft proposal at the United Nations which would declare water as a universal human right. Two years later in May 2012 Canada revised its position ("Canada Declares Support for Human Right to Water: Now is the time for action, says Council of Canadians," 2012). This needs to be better reflected in the public discourse, so that rather than having a discussion about whether water is a human right, having a discussion about what the implications of water being a human right are. The concern many of the students expressed about water being a commodity or a private resource indicates some level of interest in making water a human right, but more information about the declaration making water a human right will benefit understanding.

\subsection{Limitations}

Due to the nature of recruitment, the researchers could not control for ethnicity, gender, age and other characteristics of the students. There may not be, for example, any indigenous person or transsexual person in the focus groups. This may limit the range of perspectives in the study. As well, the study used a small, defined sample of participants, a sample size that is not large enough to look at other demographics. Thus, although students have a range of different backgrounds that may influence their ideas and thoughts on water management, the recruitment process was seeking only academic backgrounds, and so ethnic, rural and other backgrounds that may have influenced the student's perceptions and beliefs were not included.

\section{Conclusion}

In general, the students were in support of protection, conservation, sustainability, and a multi-disciplinary approach. The amount of change necessary or desired was the most debated topic. The similarities were most common amongst the ENSC and ENG students, who discussed various solutions including education, awareness campaigns, and technology, while the ECON students tended to stick to solutions using monetary and fiscal remedies and the MDSC students focused on finding solutions which would be accepted by the public. The ideas that came from the groups were insightful and many students showed particular interest in the topic; this could indicate an opportunity to reach out to students for ideas and involvement in water management. By providing funded, multi-disciplinary research opportunities for students, more ideas and solutions could be uncovered.

Water security means securing water sources not only for the present, but also for the future (Grey \& Sadoff, 2007). Water management is a critical part of maintaining the availability and quality of water (R. B. Jackson, et al., 2001). Much of the discussion in the focus groups concentrated on reducing water consumption, which is a key component in the sustainability and water security agenda. The students offered many ideas about reducing consumption, such as integrating water awareness into the education system, increasing the price of water per cubic meter, and incentivizing different conservation methods. These ideas could be employed into future water management in Calgary. There were also ideas about including the public, private, and academic sectors in water management; although the City of Calgary already addresses this idea, making participation easier and more 
well-known through social media would be beneficial. A more multi-sectoral approach improves policy uptake, as more views are represented. The students showed support for adding more money to environmental protection; further research into the publics' opinion on an increased budget would be beneficial. According to the students, Calgary is on the right track but there are still improvements to be made. Participation in water management will not only provide information for the management side, but will offer the citizen a chance to engage, learn and contribute to the future of water.

It is critical that any water directive or policy that transcends boundaries is integrated and equal amongst the different parties involved (Mostert, 2003b). This does not have to mean a water management policy that crosses geographical boundaries, but one that crosses sectors of society, such as industrial, public and individual. Public participation should extend to all sectors of society, and while this study used students in particular, future research that includes others sectors ought to use similar methodology for all groups.

\section{References}

2012 RBC Canadian Water Attitudes Survey. (2012). In R. B. W. Project (Ed.). Royal Bank of Canada.

Alexander, K. (2011). Community attitudes towards Managed Aquifer Recharge and stormwater use in Adelaide, Australia. Canberra: CSIRO Ecosystems Sciences.

Baird, J., Carter, B., Cave, K., Dupont, D., General, P., King, C., . . . Varewyck, A. (2013). Gaining Insights About Water: The Value of Surveys in First Nations Communities to Inform Water Governance. Indigenous Policy Journal, 23(4).

Becher, T. (1994). The significance of disciplinary differences. Studies in Higher education, 19(2), 151-161. http://dx.doi.org/10.1080/03075079412331382007

Becher, T., \& Trowler, P. (2001). Academic tribes and territories: Intellectual enquiry and the culture of disciplines. McGraw-Hill International.

Canada Declares Support for Human Right to Water: Now is the time for action, says Council of Canadians. (2012, June 19, 2014).

Chess, C., Hance, B. J., \& Gibson, G. (2000). Adaptive participation in watershed management. Journal of Soil and Water Conservation, 55(3), 248-252.

Conley, A., \& Moote, M. A. (2003). Evaluating Collaborative Natural ResourceManagement. Society \& Natural Resources, 16(5), 371-386. http://dx.doi.org/10.1080/08941920309181

Creswell, J. W. (2013). Research design: Qualitative, quantitative, and mixed methods approaches. Sage.

Creswell, J. W., \& Miller, D. L. (2000). Determining validity in qualitative inquiry. Theory into practice, 39(3), 124-130. http://dx.doi.org/10.1207/s15430421tip3903_2

Doria, M. (2006). Bottled water versus tap water: understanding consumers-preferences. Journal of Water Health, $271,276$.

Dupont, D. P. (2005). Tapping into consumers' perceptions of drinking water quality in Canada: Capturing customer demand to assist in better management of water resources. Canadian Water Resources Journal, 30(1), 11-20. http://dx.doi.org/10.4296/cwrj300111

Engage! Policy Statement. (2004). Calgary: The City of Calgary.

Evans, A., \& Varma, S. (2009). Practicalities of participation in urban IWRM: Perspectives of wastewater management in two cities in Sri Lanka and Bangladesh. Natural resources forum, 33, 19-28. http://dx.doi.org/10.1111/j.1477-8947.2009.01205.x

Giacalone, K., Mobley, C., Sawyer, C., Witte, J., \& Eidson, G. (2010). Survey Says: Implications of a Public Perception Survey on Stormwater Education Programming. Journal of Contemporary Water Research \& Education, 146(1), 92-102. http://dx.doi.org/10.1111/j.1936-704X.2010.00395.x

Glaser, B. G., \& Strauss, A. L. (1967). The discovery of grounded theory: Strategies for qualitative research.

Gleick, P. H. (2008). China and water. The world's water, 7, 79-100.

Grey, D., \& Sadoff, C. W. (2007). Sink or swim? Water security for growth and development. Water policy, 9(6). http://dx.doi.org/10.2166/wp.2007.021

Griffin, C. B. (1999). Watershed Councils: An Emerging Form of Public Participation in Natural Resource Management. JAWRA Journal of the American Water Resources Association, 35(3), 505-518. 
http://dx.doi.org/10.1111/j.1752-1688.1999.tb03607.x

Heidmets, M., \& Raudsepp, M. (2001). A conceptual framework for studying environmental mentality and behavior. Trames, 5(3), 198-210.

Hu, Z. (2011). Water quality perceptions in the US. ProQuest Dissertations and Theses.

Jackson, R. B., Carpenter, S. R., Dahm, C. N., McKnight, D. M., Naiman, R. J., Postel, S. L., \& Running, S. W. (2001). Water in a changing world. Ecological applications, 11(4), 1027-1045. http://dx.doi.org/10.1890/1051-0761(2001)011[1027:WIACW]2.0.CO;2

Jackson, S., Tan, P. L., \& Altman, J. (2009). Indigenous Fresh Water Planning Forum: Proceedings, Outcomes and Recommendations. National Water Commission, Canberra.

Janssen, M. A., Goosen, H., \& Omtzigt, N. (2006). A simple mediation and negotiation support tool for water management in the Netherlands. Landscape and urban planning, 78(1), 71-84. http://dx.doi.org/10.1016/j.landurbplan.2005.05.005

Jones, A. Q., Dewey, C. E., Doré, K., Majowicz, S. E., McEwen, S. A., Waltner-Toews, D., . . Mathews, E. (2005). Public perception of drinking water from private water supplies: focus group analyses. BMC Public Health, 5(1), 129. http://dx.doi.org/10.1186/1471-2458-5-129

Jonsson, A. (2005). Public participation in water resources management: Stakeholder voices on degree, scale, potential, and methods in future water management. AMBIO: A Journal of the Human Environment, 34(7), 495-500.

Koenig, T. (2004). Routinizing frame analysis through the use of CAQDAS. Paper presented at the RC33, Amsterdam, Amsterdam, The Netherlands. http://www.restore.ac.uk/lboro/research/methods/routinizing_frame_analysis_RC33.pdf

Larson, K. L., \& Lach, D. (2008). Participants and non-participants of place-based groups: An assessment of attitudes and implications for public participation in water resource management. Journal of Environmental Management, 88(4), 817-830. http://dx.doi.org/10.1016/j.jenvman.2007.04.008

MacMillan, K. (2005). More than just coding? Evaluating CAQDAS in a discourse analysis of news texts. Paper presented at the Forum Qualitative Sozialforschung/Forum: Qualitative Social Research.

Mankiw, N. G. (2011). Principles of economics. South-Western Pub.

McDaniels, T. L., Gregory, R. S., \& Fields, D. (1999). Democratizing risk management: Successful public involvement in local water management decisions. Risk Analysis, 19(3), 497-510. http://dx.doi.org/10.1111/j.1539-6924.1999.tb00424.x

Millennium Development Goals Report 2013. (2013). Millennium Development Goals Report. New York: United Nations.

Mostert, E. (2003a). The challenge of public participation. Water policy, 5(2), 179-197.

Mostert, E. (2003b). The European water framework directive and water management research. Physics and Chemistry of the Earth, Parts A/B/C, 28(12), 523-527. http://dx.doi.org/10.1016/S1474-7065(03)00089-5

Natural Resource. (2005). OECD.

Newig, J., Pahl Wostl, C., \& Sigel, K. (2005). The role of public participation in managing uncertainty in the implementation of the Water Framework Directive. European Environment, 15(6), 333-343. http://dx.doi.org/10.1002/eet.398

Noga, J., \& Wolbring, G. (2013). Perceptions of Water Ownership, Water Management, and the Responsibility of Providing Clean Water. Water, 5(4), 1865-1889. http://dx.doi.org/10.3390/w5041865

Noy, C. (2008). Sampling knowledge: The hermeneutics of snowball sampling in qualitative research. International Journal of social research methodology, 11(4), 327-344. http://dx.doi.org/10.1080/13645570701401305

Orne-Gliemann, M. (2008). Water users' associations from the users' perspective: Local water management at Thabina Irrigation Scheme, Limpopo, South Africa. TD: The Journal for Transdisciplinary Research in Southern Africa, 4(1), 1-29.

Pahl-Wostl, C., Jeffrey, P., Isendahl, N., \& Brugnach, M. (2011). Maturing the new water management paradigm: Progressing from aspiration to practice. Water Resources Management, 25(3), 837-856. 
http://dx.doi.org/10.1007/s11269-010-9729-2

Poland, B. D. (1995). Transcription quality as an aspect of rigor in qualitative research. Qualitative inquiry, 1(3), 290-310. http://dx.doi.org/10.1177/107780049500100302

Priscoli, J. D. (2004). What is public participation in water resources management and why is it important? Water International, 29(2), 221-227. http://dx.doi.org/10.1080/02508060408691771

Rinaudo, J. D., \& Garin, P. (2005). The benefits of combining lay and expert input for water-management planning at the watershed level. Water policy, 7(3), 279-293.

Scoullos, M. (2012). Transboundary IWRM Attempts in the Mediterranean Emphasis on the Drin River Case and the Involvement of Stakeholders Integrated Water Resources Management in the Mediterranean Region (pp. 3-23). Springer.

Sefton, C., \& Sharp, L. (2007). What people think about water: Lessons in citizen communication and involvement. NOVATECH 2007.

The 2013 Great Alberta Flood: Progress Report on Actions to Mitigate, Manage and Control Flooding. (2014). Calgary: Alberta Water Smart.

Tongco, M. D. C. (2007). Purposive sampling as a tool for informant selection. Ethnobotany Research and Application, 5, 147-158.

Warriner, G. K., Madden, J. J., McSpurren, K., \& Lukasik, L. (1996). Public participation in watershed management: A comparative analysis. Canadian Water Resources Journal, 21(3), 253-273. http://dx.doi.org/10.4296/cwrj2103253

Water Efficiency Plan: 30-in-30, by 2033. (2005). Calgary: The City of Calgary, Water Resources Calgary.

Webler, T., \& Tuler, S. (2001). Public participation in watershed management planning: Views on process from people in the field. Human Ecology Review, 8(2), 29.

Webster, M. (2006). Merriam-Webster Online Dictionary.

Weisenfeld, U., \& Ott, I. (2011). Academic discipline and risk perception of technologies: An empirical study. Research Policy, 40(3), 487-499. http://dx.doi.org/10.1016/j.respol.2010.12.003

What are human rights? (2012). United Nations Human Rights. Retrieved from http://www.ohchr.org/en/issues/pages/whatarehumanrights.aspx

Wutich, A., Lant, T., White, D. D., Larson, K. L., \& Gartin, M. (2010). Comparing focus group and individual responses on sensitive topics: a study of water decision makers in a desert city. Field Methods, 22(1), 88-110. http://dx.doi.org/10.1177/1525822X09349918

Note

Note 1. Commas in the quotes indicate pauses in the speakers voice

\section{Appendix A}

\section{Focus Group Questions}

A water policy is a document which targets anything related to water governance. This means that a water policy addresses aspects of water allocation, consumption, and disposal; essentially, anything that has to do with human interaction with water. It is the province of Alberta which sets standards for water management, healthy lakes, drinking and waste water systems and the use water in hydraulic fracturing. In Calgary, the current water policies address: Toilet Rebates, Water and Wastewater Rates, Drinking Water,etc.

The purpose of this focus group is to develop a new water policy for Calgary. You can ask me any questions. Please say your assigned number before speaking.

1. What do you think water is: a human right, a private resource, a public resource, a natural resource and/or a commodity?

2. What would be the primary focus of the policy? Or would you focus on multiple areas? Why do you think this (these) area(s) of water management should be the primary focus for a water policy in Calgary?

3. Will there be a single governing body implementing and monitoring this policy, or multiple? Who and why do 
you think this (these) group(s) is (are) the best for the job?

4. Currently in Calgary (population 1.097 million), clean drinking water and some other water utilities are fully funded by user fees. $\$ 35$ million goes to wastewater treatment and disposal, and the budget for environmental safety and management, meaning environmental protection, which includes water, is $\$ 8$ million. This can be compared to the city of Regina (population 193100 ), which spent $\$ 8.6$ million on operating and upgrading the wastewater collection system. We can also compare the $\$ 35$ million spent in Calgary on wastewater treatment and disposal to $\$ 18.9$ million dollars spent on police services, and the $\$ 819.3$ million spent on Transit services. Based on these numbers, what kind of budget would you set for water? If during this policy making period any new and costly ideas arise, you will have to determine how this will be paid for.

5. In 2012, Calgarians used an average of 237 litres per capita of water per day in a household (according to The City of Calgary website). To put this into reference, in 2008 Calgarians used about 280 litres and in 2003 Calgarians used about 325 litres. The average Canadian currently uses 327 litres of water a day, the average citizen of the UK uses 150 litres of water a day and the average person living in a slum in India uses less than six litres. Do you think the level of consumption Calgary is at now is appropriate?

6. Given the level of consumption you chose, what is the best way to achieve this level? How will you enforce any actions? Would there be any restrictions on water use or water consumption levels? What would be the charge for water usage?

Current rates:

Metered rate

Service charge $(\$ / 30$ days $)=\$ 14.67$

Usage rate $(\$ /$ cubic meter $)=\$ 1.60$

Flat rate

$\$$ /thousand square foot of actual lot area $=\$ 5.47$

$\$$ thousand square foot of gross building area $=\$ 17.07$

7. In times of water scarcity, Alberta follows the "First in Time, First in Right" system (legislated in 1931), which means that those who have more senior licenses which grant them right to drawing water from their designated body of water or aquifer are the first in line to get their full share of water. Given the opportunity, would you change this? If so, how would water be allocated?

8. In terms of our lakes, rivers and other bodies of water, to what extent should these protected? How? What kind of budget would this have/would you increase the budget for this? Currently protected by the Water Act and government representatives. Currently, the Environmental Safety and Management plan is responsible for identifying and addressing emerging environmental issues including groundwater quality and quantity, urban air quality concerns, sustainability, and other issues that may have long-term effects on the environment or health of Calgarians, at $\$ 8$ million annually.

9. How would pollution be addressed, considering different types of pollution (i.e. human, animal)?

10. Hydraulic fracturing uses 5 million gallons of water per well, and there are currently around 17000 wells in Alberta. To this into reference, that means each well has the same amount of water that can be used to water a golf course for 22.5 days (http://www.hydraulicfracturing.com/Water-Usage/Pages/Information.aspx). This means that in Alberta, the 17000 wells are full of enough water to water a golf course for almost 1048 years. Hydraulic Fracturing is currently an accepted practice in Alberta (the cost of water for oil and gas companies is unreported). Given the opportunity, would you change anything? Why and how?

11. How will you know if your policy has been effective? Who should be in charge of evaluating the effects of the policy? When should evaluation begin, and how often should it be monitored? 


\section{Appendix B}

\section{Tables}

Table 1. Number of students in focus groups

\begin{tabular}{ll}
\hline Focus Groups & \# of participants \\
\hline Medical Science 1 & 2 \\
Medical Science 2 & 2 \\
Medical Science 3 & 7 \\
Engineering 1 & 3 \\
Engineering 2 & 3 \\
Engineering 3 & 2 \\
Economics 1 & 4 \\
Economics 2 & 2 \\
Economics 3 & 3 \\
Environmental Science 1 & 2 \\
Environmental Science 2 & 5 \\
Environmental Science 3 & 2 \\
\hline
\end{tabular}

Table 2. Themes and codes hit counts

ECON ENG ENSC MDSC TOTALS:

\section{Things to address in Calgary}

Water quality

Price of water

421

Affordability

Flat rate

Metered rate

Willingness to pay

Accessibility

Water availability

Security

Preparedness

Calgary 2013 Flood

Sustainability

Treatment

40

2

9

12

4

5

5

0

0

0

0

7

Increase environmental protection

Protect environment

Protect water

Pollution

Prevent waste

Conservation

Decrease consumption

Awareness

$5 \quad 10$

6

4

1

7

0

6

29

9

15

10

55

0

(1)

1

11

$$
9
$$

1

4

2

$$
6
$$

8

27

7

3

16

6

1

16

2

4

$$
23
$$

8

1

3

5

8

2

3

$\begin{array}{ll}2 & 3 \\ 6 & 10\end{array}$

10

$\begin{array}{ll}3 & 10\end{array}$

$10 \quad 31$

$\begin{array}{lll}12 & 5 & 32\end{array}$

$\begin{array}{lll}3 & 3 & 18\end{array}$

Media Awareness

Citizen engagement

23

20

3

$\begin{array}{lll}11 & 7 & 36 \\ 25 & 8 & 56\end{array}$

$\begin{array}{lll}25 & 7 & 56 \\ 13 & 12\end{array}$

$\begin{array}{lll}13 & 14 & 38\end{array}$

$\begin{array}{lll}30 & 23 & 104\end{array}$

$\begin{array}{lll}31 & 5 & 65 \\ 1 & 4 & 10 \\ 8 & 3 & 13\end{array}$


Education

Value of water

3

Efficiency

6

3

4

2

10
8
11

4

The budget for water management

Money for water

$9-23$

Costs

Funding

Investment

Who is involved in water management

Expert voice

Academic voice

Government

Private sector

Public voice

Neutral party

Multi-level

Multi-sectoral

Accountability

Responsibility

Change

Change practice

Change habits

Lifestyle

Change perspective

Restriction

Incentive

Regulations

Awareness

Policing

Penalties

Status quo

No restrictions

Out of our hands

8

2

2

10

2

18

29

5

23
7

$\begin{array}{lll}23 & 9 & 64 \\ 12 & 9 & 36 \\ 5 & 3 & 15 \\ 1 & 3 & 6\end{array}$

1

13

6

4

0

(1)

(1)

3

11

1

1

13

6

4

0

1

10

35

$\begin{array}{llll}7 & 11 & 2 & 21 \\ 1 & 7 & 2 & 11 \\ 9 & 22 & 11 & 55 \\ 0 & 4 & 10 & 20 \\ 8 & 12 & 7 & 31 \\ 1 & 9 & 8 & 18 \\ 1 & 1 & 3 & 6 \\ 10 & 13 & 3 & 27 \\ 5 & 9 & 6 & 23 \\ 3 & 7 & 2 & 23\end{array}$$$
4
$$$$
0
$$

5

10

10

9

2

0

4

\section{Evaluation}

Calgary rocks

Canada rocks

Monitoring

On the right track

Goals

Room for improvement

\section{Challenges}

High consumption

Unsustainable

2

0

$\begin{array}{llll}17 & 6 & 6 & 30 \\ 3 & 0 & 1 & 5 \\ 3 & 21 & 5 & 30 \\ 2 & 1 & 0 & 4 \\ 9 & 2 & 1 & 12 \\ 1 & 6 & 2 & 9\end{array}$




\section{Perceptions}

Human right

$\begin{array}{lllll}20 & 10 & 9 & 9 & 48 \\ 18 & 34 & 31 & 31 & 114 \\ 13 & 14 & 13 & 13 & 53 \\ 7 & 2 & 4 & 9 & 22 \\ 6 & 3 & 1 & 0 & 10 \\ 4 & 6 & 7 & 1 & 18 \\ 4 & 4 & 2 & 4 & 14 \\ 0 & 4 & 3 & 8 & 15 \\ 0 & 0 & 3 & 2 & 5 \\ & & & & \\ 4 & 0 & 19 & 0 & 23 \\ 9 & 0 & 2 & 6 & 17 \\ 1 & 1 & 0 & 6 & 8 \\ 0 & 1 & 0 & 0 & 1\end{array}$

\section{Copyrights}

Copyright for this article is retained by the author(s), with first publication rights granted to the journal.

This is an open-access article distributed under the terms and conditions of the Creative Commons Attribution license (http://creativecommons.org/licenses/by/3.0/). 